\title{
Preoperative Bariatric Surgery Predictors of Type 2 Diabetes Remission
}

\author{
Joshua Fultang ${ }^{1,2}$, Ugochukwu Chinaka ${ }^{1,2}$, Jean Rankin², Andisheh Bakhshi' ${ }^{2}$, Abdulmajid Ali ${ }^{1,2, *}$ \\ ${ }^{1}$ Bariatric Surgery Unit, University Hospital Ayr, Ayrshire; ${ }^{2}$ School of Health and Life Sciences University of the West of Scotland, Ayrshire, UK
}

Obesity represents a significant proportion of the global public health burden, with the World Health Organization (WHO) estimating more than 600 million people are affected worldwide. Unfortunately, the epidemic of obesity is linked to the increased prevalence of associated metabolic diseases such as type 2 diabetes mellitus (T2DM). Bariatric surgery as an intervention has been shown to provide sustainable weight loss, and also leads to superior short- and long-term metabolic benefits including T2DM remission. Despite this added advantage conferred by bariatric surgery, emerging evidence has shown that not all patients with T2DM achieve remission postoperatively. As such, to improve patient selection and optimize preoperative counselling, research has focused on the preoperative predictors of T2DM remission following bariatric surgery. Herein, we provide a critical review of the current literature addressing preoperative predictors of T2DM remission and highlight the current gaps in the literature. The review comprised a multistage advanced electronic search of the Ovid/Medline, Embase, and Cochrane online libraries to identify available studies published over the last decade.

Key words: Outcome, Bariatric surgery, Diabetes remission, Type 2 diabetes mellitus
Received July 31, 2020

Reviewed August 30, 2020

Accepted November 25, 2020

*Corresponding author Abdulmajid Ali

(i) https://orcid.org/0000-0001-9473-4950

Bariatric Surgery Unit, University Hospital Ayr, Ayrshire, Scotland KA6 6DX, UK

Tel: +44-1292-886666

Fax: +44-1292-886666

E-mail:abdulmajidali@hotmail.com

\section{INTRODUCTION}

The last few decades have been dominated by an ever-increasing global obesity epidemic. The World Health Organization estimated that in 2016 close to two billion individuals were overweight (body mass index [BMI], 25-29.9 kg/m²) and more than $600 \mathrm{mil}-$ lion were obese $\left(\mathrm{BMI}>30 \mathrm{~kg} / \mathrm{m}^{2}\right)$ worldwide. ${ }^{1}$ The direct consequence of this burden of obesity is the concomitant increase in the prevalence of associated comorbidities, and of type 2 diabetes mellitus (T2DM) in particular. ${ }^{2}$ Management of chronic hyperglycemia secondary to T2DM is achieved by medication and lifestyle modifications. ${ }^{2,3}$ The metabolic benefits of these lifestyle modifications are underpinned by weight loss and are generally limited to short- and mid-term improvements. ${ }^{2,3}$ Since its inception, bariatric surgery has produced superior and more long-term weight loss and T2DM remission. ${ }^{2,4,5}$
In the early 1990s, Pories et al. ${ }^{6}$ reported significant long-term improvement in glycemic control of obese patients with T2DM following bariatric surgery. In a subsequent study with 14 years follow up, the researchers found $82.9 \%$ of patients with T2DM were able to maintain euglycemia. This study was the first documentation of bariatric surgery as a potential "cure" for T2DM. The researchers also observed that younger patients and those with a shorter duration of T2DM were more likely to go into remission postoperatively. ${ }^{8}$

More evidence supporting the role of bariatric surgery in the treatment of T2DM emerged in the early 2000s. Six key studies were published, including one randomized control trial (RCT), ${ }^{9}$ three prospective ${ }^{10-12}$ and two retrospective ${ }^{13,14}$ cohort studies. These studies consistently showed that bariatric surgery patients had significantly greater postoperative T2DM remission rates (up to $86 \%) .{ }^{14}$ Another pivotal study was the prospective, controlled Swedish Obese Subjects (SOS) study where $72 \%$ of patients self-

Copyright (C) 2021 Korean Society for the Study of Obesity

(a) This is an Open Access article distributed under the terms of the Creative Commons Attribution Non-Commercial License (https://creativecommons.org/licenses/by-nc/4.o/) which permits unrestricted non-commercial use, distribution, and reproduction in any medium, provided the original work is properly cited. 
reported remission at 2 years postoperatively. ${ }^{15}$

The American Diabetes Association (ADA) multidisciplinary expert panel reached a consensus on the definition of T2DM remission in 2009 in an attempt to distill the available evidence. ${ }^{16}$ This consensus statement defined the types of remission as follows.

(1) Partial remission: glycemic indices fall into the pre-diabetic range (glycosylated hemoglobin [HbA1c], 5.7\%-6.4\%; fasting plasma glucose [FPG], 100-125 mg/dL) for at least 1 year; (2) complete remission: restoration of normoglycemia (HbAlc, < 5.7\%; FPG, $<100 \mathrm{mg} / \mathrm{dL}$ ) for at least 1 year; (3) prolonged remission: complete remission of at least 5 years' duration.

Since the ADA consensus, many studies have focused on T2DM remission and its preoperative, operative and postoperative predictors. This literature review aimed to utilize a systematic approach to offer a critical assessment of current evidence addressing T2DM remission, with a particular focus on the identification of preoperative predictors of remission.

\section{SEARCH STRATEGY AND STUDY SELECTION}

An advanced multistage electronic search was performed in December of 2019 using the Ovid/Medline, Embase, and Cochrane online libraries to identify available studies relevant to the subject. Only studies published within the last decade were reviewed.

The exclusion criteria included all publications with abstracts only, studies with no surgical intervention, animal studies, case reports, studies in T2DM patients with a BMI $<30 \mathrm{~kg} / \mathrm{m}^{2}$, non-English language, sample size less than 50, replies to editors, comments, and duplicate studies. The main inclusion criteria were publications reporting T2DM remission following bariatric surgery and preoperative predictors of remission. A detailed Preferred Reporting Items for Systematic Reviews and Meta- Analyses (PRISMA) flow diagram is provided in Fig. 1.

Historically, predictors of T2DM remission have been grouped into preoperative factors (such as duration of diabetes [DoD], age, ethnicity, sex, baseline $\mathrm{HbAlc}$, baseline BMI), operative (type of surgery), and postoperative (postoperative weight loss, complications). The main preoperative variables that have been explored in the literature review are highlighted in Table 1.

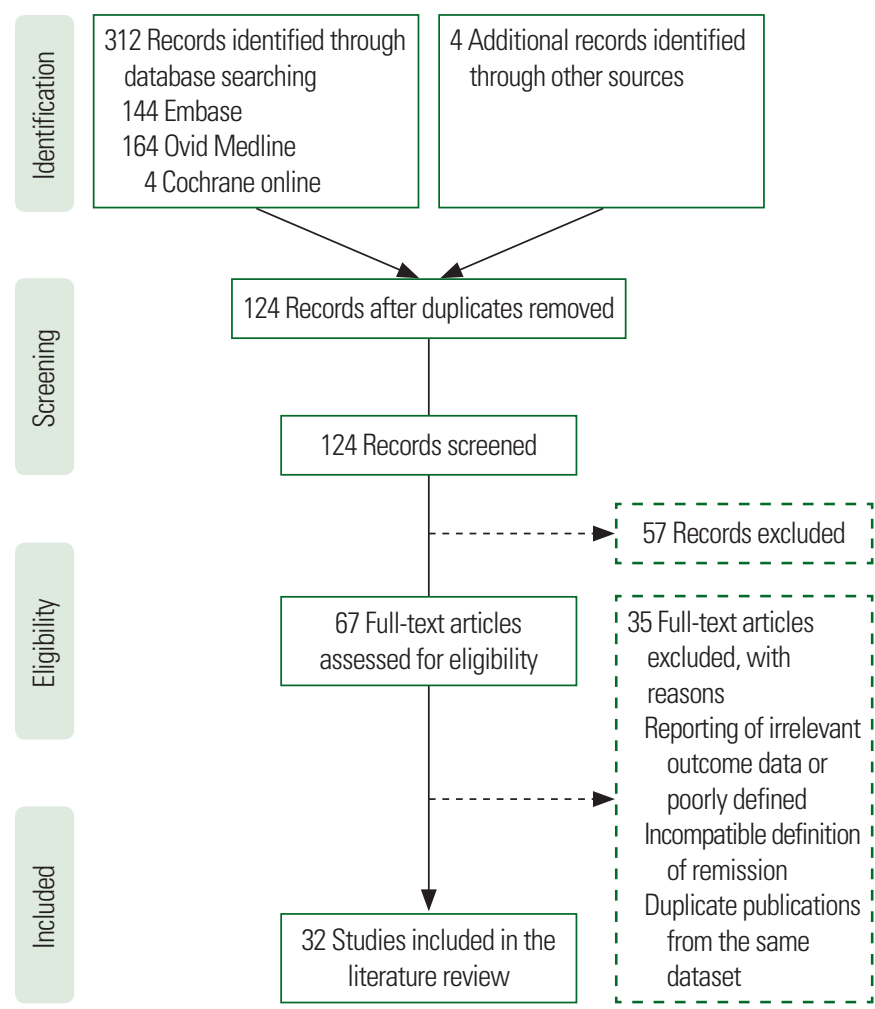

Figure 1. Preferred Reporting Items for Systematic Reviews and Meta- Analyses (PRISMA) flow diagram indicating the number of studies included in this review. The literature search yielded 316 articles. Sixty-seven of these were deemed eligible for review and 32 included in the literature review.

\section{DOD AS A PREDICTOR OF T2DM REMISSION AFTER SURGERY}

Among the preoperative factors, the $\mathrm{DoD}$ is strongly correlated with postoperative T2DM remission. Recently, one of the scoring systems (advanced-DiaRem [Ad-DiaRem]) was considered an improved version of DiaRem due to its inclusion of DoD. ${ }^{17}$

A large population-based matched cohort study $(n=1,111)$ by Madsen et al. ${ }^{18}$ with a median follow-up of 5.3 years found that patients with a $\mathrm{DoD}$ of fewer than 5 years were more likely to go into remission. Among patients with a $\mathrm{DoD}$ of greater than 5 years, the relative risk (RR) of not achieving remission as compared to patient with DoD of less than two years was 0.87 (95\% confidence interval [CI], 0.79-0.97) for DoD of 5-8 years and 0.73 (95\% CI, $0.62-0.86)$ for DoD $\geq 8$ years. ${ }^{18}$ Similarly, a 2015 meta-analysis including 13 studies of 1,555 patients found there was a statistically significant association between DoD and postoperative T2DM remission. ${ }^{19}$ The analysis indicated patients with a more recent diag- 
Table 1. Summary of included studies, study types, and preoperative predictors

\begin{tabular}{|c|c|c|c|c|c|c|c|c|c|c|c|c|}
\hline Author (year) & Study type & Procedure & $\mathrm{n}$ & Age & $\mathrm{DoD}$ & C-peptide & $\begin{array}{c}\text { Baseline } \\
\text { BMl }\end{array}$ & $\begin{array}{l}\text { Baseline } \\
\text { HbA1c }\end{array}$ & $\begin{array}{l}\text { Insulin } \\
\text { use }\end{array}$ & Sex & Race & $\begin{array}{l}\text { Scoring } \\
\text { model }\end{array}$ \\
\hline Chikunguwo et al. $(2010)^{20}$ & Retrospective & RYGB & 177 & 0 & & & & & 0 & & & \\
\hline Hamza et al. $(2011)^{21}$ & Retrospective & LAGB & 74 & 0 & & & & & & 0 & & \\
\hline Hayes et al. $(2011)^{22}$ & Prospective & $\mathrm{RYBG}, \mathrm{GB}$ & 127 & $\mathrm{~N}$ & & & 0 & 0 & 0 & & & LRM \\
\hline Carlsson et al. $(2012)^{23}$ & Prospective & RYGB, AGB, VBG & 1,658 & $\mathrm{~N}$ & 0 & & $\mathrm{~N}$ & & $\mathrm{~N}$ & & & \\
\hline Jiménez et al. $(2012)^{24}$ & Prospective & SG & 153 & & 0 & & & 0 & 0 & & & \\
\hline Lee et al. $(2013)^{25}$ & Retrospective & RYGB, GB & 63 & 0 & 0 & 0 & 0 & & & & & $\mathrm{ABCD}$ \\
\hline Arterburn et al. $(2013)^{26}$ & Retrospective & RYGB & 4,434 & & 0 & & & 0 & 0 & 0 & & \\
\hline Dixon et al. $(2013)^{27}$ & Retrospective & GB & 154 & & 0 & 0 & 0 & $\mathrm{~N}$ & & & & LRM \\
\hline Aarts et al. $(2013)^{28}$ & Retrospective & RYGB & 56 & & 0 & & $\mathrm{~N}$ & 0 & 0 & & & \\
\hline Ramos-Levi et al. (2014) ${ }^{29}$ & Retrospective & SG, RYGB, BPD & 141 & 0 & 0 & 0 & $\mathrm{~N}$ & 0 & 0 & 0 & & LRM \\
\hline Still et al. $(2014)^{30}$ & Retrospective & RYGB & 690 & 0 & 0 & & & 0 & 0 & & & DiaRem \\
\hline Robert et al. $(2013)^{31}$ & Retrospective & LAGB, RYBG, SG & 46 & & 0 & & 0 & 0 & 0 & & & \\
\hline English et al. $(2015)^{32}$ & Retrospective & RYGB & 245 & & & & & 0 & & & & \\
\hline Bhasker et al. $(2015)^{33}$ & Prospective & RYBG & 102 & 0 & 0 & 0 & 0 & & 0 & & & \\
\hline Panunzi et al. $(2016)^{34}$ & Prospective & GB, BPD, LAGB & 415 & & 0 & & 0 & 0 & 0 & & & \\
\hline Panunzi et al. $(2015)^{35}$ & Meta-analysis & SG, LAGB, GB & 4,944 & & 0 & & $\mathrm{~N}$ & 0 & & & & \\
\hline Wang et al. $(2015)^{19}$ & Meta-analysis & SG, RYGB & 1,753 & 0 & 0 & 0 & $\mathrm{~N}$ & 0 & 0 & & & \\
\hline Ikramuddin et al. $(2015)^{36}$ & RCT & RYGB & 60 & & & 0 & N & & & & & \\
\hline Schauer et al. $(2017)^{4}$ & RCT & $\mathrm{GB}, \mathrm{SG}$ & 134 & $\mathrm{~N}$ & 0 & $\mathrm{~N}$ & $\mathrm{~N}$ & $\mathrm{~N}$ & $\mathrm{~N}$ & $\mathrm{~N}$ & $\mathrm{~N}$ & \\
\hline Park et al. $(2016)^{37}$ & Retrospective & RYGB & 134 & 0 & & 0 & 0 & 0 & & & & LRM \\
\hline Scopinaro et al. $(2017)^{38}$ & Retrospective & $\mathrm{BPD}$ & 135 & & & & 0 & & 0 & & & \\
\hline Praveen Raj et al. $(2017)^{39}$ & Retrospective & RYGB, SG & 53 & & & $\mathrm{~N}$ & $\mathrm{~N}$ & 0 & & & & \\
\hline Aron-Wisnewsky et al. (2017) & Retrospective & RYGB & 213 & 0 & 0 & & & 0 & 0 & & & Ad-DiaRem \\
\hline Aminian et al. $(2017)^{40}$ & Retrospective & RYGB, SG & 659 & & 0 & & & 0 & 0 & & & IMS score \\
\hline Naitoh et al. $(2018)^{41}$ & Retrospective & $\mathrm{SG}, \mathrm{GB}$ & 298 & & 0 & & & 0 & 0 & & & \\
\hline Huang et al. $(2018)^{42}$ & Meta-analysis & SG, GBn & 1,160 & & 0 & & & 0 & & & & \\
\hline Stallard et al. $(2018)^{43}$ & Retrospective & RYGB, SG & 98 & 0 & 0 & & & $\mathrm{~N}$ & 0 & & & \\
\hline Pucci et al. $(2018)^{44}$ & Retrospective & RYGB, SG & 210 & & 0 & & & 0 & 0 & & & DiaBetter \\
\hline Madsen et al. $(2019)^{18}$ & Matched cohort & RYGB & 1,111 & 0 & 0 & & & 0 & 0 & 0 & 0 & \\
\hline Shen et al. $(2019)^{45}$ & Retrospective & SG & 128 & 0 & 0 & 0 & & & & 0 & & \\
\hline
\end{tabular}

DoD, duration of diabetes; BMl, body mass index; HbA1c, glycosylated hemoglobin; O, effect; N, neutral effect; Blank, not assessed/unclear; RYGB, Roux-en-Y gastric bypass; LAGB, Laparoscopic Adjustable Gastric Banding; GB, bypass surgery (unspecified); LRM, logistic regression model; AGB, adjustable gastric banding; VBG, vertical gastric banding; SG, sleeve gastrectomy; BPD, biliopancreatic diversion; Ad-DiaRem, advanced-DiaRem; IMS, individualized metabolic surgery; GBn, gastric bypass-non-specified.

nosis of T2DM were more likely to achieve remission postoperatively (random model; odds ratio [OR], -5.22 ; $95 \% \mathrm{CI},-7.39$ to -3.42; $P<0.01) .{ }^{19}$ A retrospective analysis of 154 patients with T2DM by Dixon et al. ${ }^{27}$ following Roux-en-Y gastric bypass (RYGB) surgery found the most important preoperative predictor of no remission to be a $\mathrm{DoD} \geq 8$ years (sensitivity of $78 \%$ and specificity of $90 \%$; area under the curve, 0.84 ).

Interestingly, the predictive value of the $\mathrm{DoD}$ is not limited to bypass surgeries as some earlier studies had indicated. ${ }^{17,34,40,45}$ Initially, none of the predictive models of T2DM remission based on the DoD included sleeve gastrectomy (SG) patients. ${ }^{45}$ However, three more recent retrospective studies that included patients who underwent SG (Aminian et al., ${ }^{40}$ Jiménez et al., ${ }^{24}$ and most recently Shen et $\mathrm{al}^{45}$ ) all showed the DoD to be a significant predictor of remission. Panunzi et al. ${ }^{34}$ analyzed data from patients recruited to the prospective SOS study and two RCTs. This analysis included 415 obese patients with diabetes who had undergone either restrictive (SG, gastric banding) or malabsorptive (gastric bypass) bariatric surgery. The results indicated the $\mathrm{DoD}$ was significantly correlated with outcome only after restrictive surgery. Patients with a DoD of up to 7.5 years went into remission following malabsorptive bariatric surgery. ${ }^{34}$ This finding was contradicted by results 
from two meta-analyses by Wang et al. ${ }^{19}$ and Huang et $\mathrm{al}^{42}$ In the most recent of these, Huang et al. ${ }^{42}$ analyzed data from five RCTs, six prospective and six retrospective studies. The analysis identified 1,160 patients with T2DM who had undergone gastric bypass or SG surgery. The DoD was one of two preoperative predictive variables to have a significant independent effect on remission regardless of the type of surgery. ${ }^{42}$

The DoD is, therefore, a significant predictor of remission; however, there is ongoing controversy as to the cutoff point at which the DoD becomes an independent predictor of T2DM outcomes. This cutoff most likely lies somewhere between a DoD of 5 to 8 years, beyond which T2DM postoperative outcomes are significantly poorer.

\section{AGE AS A PREDICTOR OF T2DM REMISSION AFTER SURGERY}

Another point of debate is the predictive value of age in T2DM remission after bariatric surgery. This is demonstrable from some of the clinical predictive tools such as the ABCD, DiaRem, and AdDiaRem scores. ${ }^{17,25,30}$ There is strong evidence that older patients are less likely to achieve remission, but the potential association of younger age with outcome remains uncertain.

In a single-center retrospective analysis of 74 patients in 2011, Hamza et al. ${ }^{21}$ showed that the risk of postoperative remission was reduced by $20 \%$ with every 12 -year increment in age. Madsen et al. ${ }^{18}$ also found that patients older than 50 years of age were unlikely to achieve remission postoperatively. Age was a strong predictor of not achieving remission among patients aged 50 to 60 years (RR, 0.88 ; $95 \% \mathrm{CI}, 0.81-0.96$ ) or $\geq 60$ years (RR, 0.83 ; $95 \% \mathrm{CI}, 0.72-$ 0.97 ) as compared to those less than 40 years of age. ${ }^{18}$ In a prospective observational study $(n=106)$, Bhasker et al. $^{33}$ found that patients 60 years of age and older had poorer outcomes in terms of remission. Similar to the conclusions of most other studies, the researchers suggested age was a rather indirect marker of pancreatic $\beta$-cell reserve. ${ }^{17,33,39}$ In a historically significant yet relatively small retrospective study $(n=63)$, Lee et $a .^{25}$ proposed the ABCD predictive scoring model for clinical T2DM remission. The researchers found that beginning at age 40, increasing age negatively impacted postoperative remission. ${ }^{25}$ Three other retrospective cohort studies have reported similar unfavorable effect of increasing age on remission..$^{29,43,45}$ A meta-analysis including a total of 1,149 patients with T2DM from 13 studies from North America, South America, Asia, Oceania, and Europe carried out by Wang et al. ${ }^{19}$ showed that even when stratified by ethnicity, preoperative age had a significant negative correlation with T2DM remission (random model; OR, -2.46 ; $95 \% \mathrm{CI},-3.90$ to -1.02 ; $P<0.01)$.

In contrast, analyses of data from the Surgical Treatment and Medications Potentially Eradicate Diabetes Efficiently (STAMPEDE) and SOS clinical trials initially designed to compare the effectiveness of bariatric surgery to intensive medical therapy in the management of T2DM, found age to have a neutral effect on remission. ${ }^{4,23}$ It is important to note that the SOS trial was a matched rather than a randomized trial, with diagnoses of T2DM based on fasting glucose concentrations and self-reported used of anti-diabetes medications. It is also worth noting that compared to the above clinical trials that found a neutral effect of age on T2DM remission after surgery, the cohorts of patients in the retrospective studies were slightly older ( 18 to 67 years of age in Lee et al. ${ }^{25}$ ).

Some researchers have suggested that there is a strong link between age and the $\mathrm{DoD}$. In an attempt to improve the predictive value of the DiaRem score proposed by Still et al..$^{30}$ with age as a direct predictor of remission, Aron-Wisnewsky et al. ${ }^{17}$ proposed the Ad-DiaRem score based on the results of a retrospective study involving 213 RYGB patients. They concluded older patients tend to have a longer $\mathrm{DoD}$ and poorer residual pancreatic function. Consequently, deploying age as an integral parameter of a scoring tool may prove to be punitive. ${ }^{17}$ It can, therefore, be concluded that age is irrelevant in younger patients (under 40 years of age), but can act as a rather indirect predictor in older patients, given older patients tend to have a longer $\mathrm{DoD}$ and invariably poorer residual pancreatic function.

\section{C-PEPTIDE AS A PREDICTOR OF T2DM REMISSION AFTER BARIATRIC SURGERY}

Another area of focus is the role of fasting and random preoperative plasma C-peptide concentrations in predicting T2DM remission following metabolic surgery. Unfortunately, fewer studies have included data on C-peptide concentrations, as C-peptide analyses 
are not usually available in routine clinical practice. ${ }^{40}$

In a retrospective analysis including 56 patients with T2DM, Aarts et $\mathrm{al}^{28}$ found that preoperative fasting $\mathrm{C}$-peptide concentrations $>1.0 \mathrm{nmol} / \mathrm{L}$ were associated with a $90 \%$ chance of remission in contrast to no remission in patients with fasting C-peptide concentrations $<1.0 \mathrm{nmol} / \mathrm{L}$. In the analyses, some patients classified as being in remission continued to take antidiabetic medication. ${ }^{28}$ Dixon et al. ${ }^{27}$ found that $89 \%$ of patients who failed to go into remission had preoperative C-peptide concentrations $<2.9 \mathrm{ng} / \mathrm{mL}$. Another retrospective study including patients who had undergone RYGB surgery $(n=134)$ reported similar results, with a baseline Cpeptide concentrations $>2.6 \mathrm{ng} / \mathrm{mL}$ considered the cutoff for diabetes remission. The investigators found baseline C-peptide concentration to be the most discriminatory preoperative variable in predicting remission. ${ }^{37}$

Different levels of C-peptide have been shown to achieve different rates of remission. High preoperative plasma C-peptide concentrations have been shown to be significantly correlated with T2DM remission in multiple retrospective and meta-analysis studies. In a prospective observational study involving 102 patients who had undergone RYGB surgery, Bhasker et l. $^{33}$ showed that fasting Cpeptide concentrations $\geq 3 \mathrm{nmol} / \mathrm{L}$ were significantly associated with remission. Remission was reported in $85 \%$ of patients with $\geq 3 \mathrm{nmol} / \mathrm{L} \mathrm{C}$-peptide and $90 \%$ of patients with $>6 \mathrm{nmol} / \mathrm{L}$ achieved remission. ${ }^{33} \mathrm{In}$ addition, C-peptide concentrations of $6 \mathrm{ng} / \mathrm{mL}$ were also associated up to $90.3 \%$ chance of remission according to Lee et al. ${ }^{25}$ All the aforementioned studies involved patients who underwent bypass surgery; however, in a retrospective study $(n=141)$ including both RYGB and SG patients, Ramos-Levi et al. ${ }^{29}$ found that high preoperative C-peptide concentrations were significantly correlated with T2DM remission $\left(\mathrm{R}^{2}, 0.249\right.$; OR, 1.652; 95\% CI, 1.181-2.309; $P=0.003) .{ }^{29}$ In a meta-analysis carried out by Wang et al., ${ }^{19}$ fasting C-peptide data was obtained for 149 patients with T2DM from two studies. Their analyses showed a significant association between remission and baseline $\mathrm{C}$-peptide concentrations.

In contrast, our literature search identified only one relatively small retrospective study (SG, 35 patients; bypass surgery, 18 patients) completed by Praveen Raj et al. ${ }^{39}$ that yielded a contradictory conclusion regarding $\mathrm{C}$-peptide. We therefore conclude that fasting C-peptide concentrations have high independent predictive power with regard to bariatric surgery outcomes. The only controversy arising from the current literature is with regard to the C-peptide cutoff concentration at which bariatric surgery with T2DM remission as the main objective can be deemed futile.

\section{BASELINE BMI AS A PREDICTOR OF T2DM REMISSION AFTER BARIATRIC SURGERY}

Baseline $\mathrm{BMI}$ as a predictive factor of T2DM remission after bariatric surgery has been assessed in multiple studies. The reported findings results are inconsistent, with the various studies suggesting neutral, negative or positive effects of baseline BMI on T2DM remission. Seven out of eight retrospective studies found in the literature search suggested higher baseline BMIs predicted better T2DM outcomes after bariatric surgery. The first study to highlight this was Lee et al., ${ }^{25}$ who reported superior remission rates in patients with higher baseline BMIs. This finding was supported by Dixon et al., ${ }^{27}$ Hayes et al., ${ }^{22}$ Bhasker et al., ${ }^{33}$ and Scopinaro et al. ${ }^{38}$ In Dixon et al.s study, ${ }^{27}$ a higher BMI ( $>35 \mathrm{~kg} / \mathrm{m}^{2}$ ) was an independent predictor of remission $(B=20.035 ; 95 \% C I, 20.056-20.016 ; P=0.001)$. The findings in the above studies were directly contradicted by Robert et al., ${ }^{31}$ who in a similar analysis that included a smaller number of patients $(n=46)$ who had undergone either LAGB, RYGB, or $\mathrm{SG}$, found patients with $\mathrm{BMI}<35 \mathrm{~kg} / \mathrm{m}^{2}$ had greater remission rates.

Six other studies, including two RCTs, ${ }^{4,36}$ two meta-analyses, ${ }^{19,35}$ and two retrospective studies, reported baseline BMI to have a neutral effect on T2DM outcomes. Panunzi et al. ${ }^{34,35}$ carried out two important studies, the first being a meta-analysis specifically designed to assess the role of baseline BMI in T2DM remission following bariatric surgery. This analysis included the largest number of patients with T2DM $(\mathrm{n}=4,944)$, and found similar rates of remission among patients with $\mathrm{BMI} \geq 35 \mathrm{~kg} / \mathrm{m}^{2}$ and those with BMI $<35 \mathrm{~kg} / \mathrm{m}^{2}$ (71\% and $72 \%$, respectively). The researchers concluded preoperative BMI was unrelated to T2DM remission. ${ }^{35}$ This finding is supported by results from two relatively small RCTs by Ikramuddin et al. ${ }^{36}$ and Schauer et al. ${ }^{4}$ In a subsequent study, Panunzi et al. $^{34}$ analyzed prospective data from the Swedish SOS trial and two RCTs to better understand the role of BMI. The researchers stratified the patients' degree of obesity as follows: BMI $<35 \mathrm{~kg} / \mathrm{m}^{2}$, 
$\mathrm{BMI} \geq 35$ to $\leq 40 \mathrm{~kg} / \mathrm{m}^{2}$, and BMI $>40 \mathrm{~kg} / \mathrm{m}^{2}$. Interestingly, they found $\mathrm{BMI} \geq 44 \mathrm{~kg} / \mathrm{m}^{2}$ to be an independent predictor of T2DM remission regardless of the bariatric surgical procedure performed. The calculated odds ratio for remission using BMI $<35 \mathrm{~kg} / \mathrm{m}^{2}$ as the reference value was 2.9 (95\% CI, 1.43-5.80) for patients with BMI $>40 \mathrm{~kg} / \mathrm{m}^{2}(P=0.003)$. The findings indicated class I and II obesity assessed by BMI played no significant role in predicting T2DM remission following bariatric surgery. ${ }^{34}$ In other meta-analyses, Wang et al. ${ }^{19}$ found baseline BMI to only play a predictive role in Asian subjects, whilst Huang et al. $^{42}$ suggested its predictive role was only relevant in patients who had undergone SG. It is important to note that in the Huang et al.s study, ${ }^{42}$ the $P$-value for the correlation of BMI with outcomes after SG surgery was close to the critical point $(P=0.048)$. Baseline BMI was also found to be an unreliable predictor of T2DM outcome by Carlsson et $\mathrm{al}^{23}$ in a prospective cohort study of data from the SOS trial. They reviewed 1,658 patients who underwent RYGB and gastric banding. Three other retrospective studies also reported a neutral effect of baseline BMI on postoperative T2DM remission; $;^{28,29,39}$ however, these studies included relatively small numbers of patients or lacked a comparable number of patients with extreme BMIs.

\section{BASELINE HbA1c AS A PREDICTOR OF T2DM REMISSION AFTER BARIATRIC SURGERY}

Preoperative $\mathrm{HbAlc}$ is a frequently reported to be significantly correlated with T2DM remission. Elevated $\mathrm{HbAlc}$ concentrations are an indication of poorer glycemic control and act as a marker of the severity of T2DM and/or reflect suboptimal medical treatment. Evidence shows patients with greater elevations in baseline HbAlc have a poorer DM outcome; however, this use of this variable as an independent predictor of remission remains controversial.

Twelve retrospective studies identified in the literature search reported lower baseline $\mathrm{HbAlc}$ to be associated with higher remission rates. ${ }^{17,26,28-32,39-41,44,45}$ Among these, Robert et al. ${ }^{31}$ found this association to be significant irrespective of the type of surgery. In two prospective studies by Hayes et al. ${ }^{22}$ and Jiménez et al. ${ }^{24}$ in which the outcomes of 127 gastric bypass and 153 SG patients were reviewed, respectively, preoperative $\mathrm{HbAlc}$ was a significant predic- tor of remission. Interestingly, some studies that took into account more specific markers of T2DM severity could not validate $\mathrm{HbAlc}$ as an independent predictor of remission. ${ }^{27,33,45}$ These findings are supported by the fact that only one predictive model includes both HbAlc and C-peptide. ${ }^{37}$ Furthermore, the RCT completed by Ikramuddin et $\mathrm{al}^{36}$ that included 60 T2DM RYGB patients, the only statistically significant univariate predictor of T2DM was the baseline C-peptide concentration, and not HbAlc. The other RCT we identified reported the baseline $\mathrm{HbAlc}$ concentration to be unrelated to remission. ${ }^{4}$ These studies indicate a lower preoperative $\mathrm{HbAlc}$ is associated with postoperative remission, but the role of $\mathrm{HbAlc}$ as an independent predictor of remission is limited.

\section{PREOPERATIVE INSULIN THERAPY AS A PREDICTOR OF T2DM REMISSION AFTER BARIATRIC SURGERY}

Preoperative use of insulin is the second most reported predictor of poorer outcomes after bariatric surgery. An early aberration to its function as a predictor worth noting is insulin usage is based on local guidelines. This is illustrated in $23.3 \%$ usage rates in the UK compared to $8.1 \%$ in the United States. ${ }^{46}$ The literature search identified seven retrospective studies involving both bypass and SG patients for which insulin use was correlated with poorer T2DM outcomes. In one of these, Naitoh et al. ${ }^{41}$ (SG, 101 patients; laparoscopic sleeve gastrectomy with duodenojejunal bypass, 52 patients) found the lack of insulin use to be a significant independent predictor of better postoperative remission (OR, 4.247; 95\% CI, 1.797-10.034). The authors ${ }^{41}$ suggested that patients on insulin should be offered malabsorptive rather than SG surgery to increase their likelihood of remission. The role of preoperative insulin use as a predictor of T2DM outcomes in cohorts of SG patients was also significant in the Jiménez et al.'s ${ }^{24}$ and Shen et al.'s ${ }^{45}$ studies. In a prospective analysis of data from two RCTs and the SOS trial $(n=415)$, Panunzi et al. ${ }^{34}$ reported insulin use as an independent predictor of remission only in purely restrictive procedures such as SG.

Among all meta-analyses identified in the literature search, only Wang et al. ${ }^{19}$ analyzed the role of preoperative insulin use. They identified 1,350 patients with T2DM from 10 studies who had been using insulin when they had undergone either restrictive or 
malabsorptive surgery. Their analyses showed a significant association between insulin use and T2DM remission (random model; OR, 0.15 ; 95\% CI, $0.11-0.20 ; P<0.01)$ irrespective of surgical type. ${ }^{19}$ The literature search also identified nine studies (prospective, $n=2$; retrospective, $n=7$ ) involving patients who had undergone bypass surgery. ${ }^{17,20,22,26-28,30,38,43}$ All of these studies reported insulin use to be significantly correlated with poorer T2DM outcomes. None of the studies suggested insulin was an independent predictor of remission. As highlighted above, patients using insulin are likely to have a longer DoD and lower plasma C-peptide concentrations, and global insulin use is not consistent. ${ }^{47}$ The findings of the Chong et al.s study ${ }^{47}$ that included $30 \%$ Taiwanese and $60 \%$ American patients who were using insulin preoperatively support the above position, and showed insulin use was unrelated to remission. More robust studies assessing the influence of regional variation in preoperative insulin use and of obesity class on the outcomes of bariatric surgery are therefore warranted.

\section{GENDER AS A PREDICTOR OF T2DM REMISSION AFTER BARIATRIC SURGERY}

There is limited evidence to support the role of gender as a preoperative predictor of T2DM remission after bariatric surgery. Few studies have found female gender to be a significant predictor of a better outcome. In a multivariate analysis, Hamza et al. ${ }^{21}$ found male patients were 17 times less likely to achieve additional percent excess weight loss (\%EWL) postoperatively compared to females. They found being female to be an independent predictor of $\% \mathrm{EWL}$ and \%EWL to be an independent predictor of DM remission. In a relatively recent National Health Service-based retrospective analysis of 210 bariatric patients who had undergone RYGB or SG surgery, Pucci et al. ${ }^{44}$ found that regardless of surgery type, the female gender was associated with higher remission at 2 years postoperatively. The above findings were contradicted by Ramos-Levi et al. ${ }^{29}$ and Arterburn et al. $^{26}$ in two retrospectives analyses. Ramos-Levi et al. ${ }^{29}$ found female gender had a negative influence on remission as it remained a significant predictor of poorer outcome in three out of four models in the multivariate analyses. In the largest retrospective analysis identified by the literature search $(4,434$ patients with T2DM), Arterburn et al. ${ }^{26}$ found all multivariable-adjusted models showed women were significantly less likely to achieve remission than men (hazard ratio, 0.81 ; 95\% CI, 0.74-0.90). Chikunguwo et $\mathrm{al}^{20}$ also showed that DM remission was significantly more durable in males $(80 \%)$ than in females $(52.3 \%, P=0.0144)$. However, the majority of studies, including RCTs, have found gender to have a neutral effect on remission. ${ }^{4,23}$ Of note, in a meta-analysis of seven 1,113 patients with T2DM, Wang et al. ${ }^{19}$ found gender to have no significant influence on remission outcome, and none of the current preoperative scoring models include gender as a marker of outcome.

\section{ETHNICITY AS A PREDICTOR OF T2DM REMISSION AFTER BARIATRIC SURGERY}

A limited number of studies have addressed the effect of ethnicity on T2DM remission after bariatric surgery. The obvious difficulty for most of the retrospective regional studies is the attainment of a sufficiently ethnically diverse cohort for the analysis of race to be statistically robust. ${ }^{26}$ Most studies attempting to assess race as a preoperative predictor of outcome have shown race is unrelated to DM remission. A meta-analysis by Admiraal et al. ${ }^{48}$ specifically designed to assess the role of ethnicity in DM outcomes among Caucasian and African Americans following bariatric surgery identified 14 studies, with only three reporting data for DM remission. From these studies, analyses of pooled data including 195 African American and 342 Caucasian participants showed DM remission was slightly more frequent in African Americans (1.41; 95\% CI, 0.563.52 ), but this difference was not statistically significant. ${ }^{48}$ In a retrospective analysis of 245 patients following RYGB surgery, English et al. ${ }^{32}$ found patients who did and did not achieve remission to be $79 \%$ and $88 \%$ Caucasian, respectively. The investigators found race was unrelated to remission $(P=0.067)$. The evidence to support racial differences in response to bariatric surgery is relatively sparse. An example of note is the RCT involving Taiwanese and American subjects. The researchers concluded that there were slight ethnic differences in T2DM response post-RYGB and attributed the insignificant results $(P=0.08)$ to the small number of patients included. However, $100 \%$ of the Taiwanese patients were reported to be Asian and there were significant national differences in the baseline characteristics, such as BMI $\left(31.9 \pm 1.7\right.$ vs. USA, $32.9 \pm 1.5 \mathrm{~kg} / \mathrm{m}^{2} ; P=$ 
$0.016)$, duration of insulin use (6.1 \pm 3.6 vs. USA, $10.4 \pm 6.5$ years; $P=0.0006)$, age ( $45.7 \pm 7.9$ vs. USA, $50.7 \pm 8.9$ years; $P=0.014)$, to name a few. ${ }^{46}$ We therefore concluded that race is very unlikely to play an important role in predicting T2DM remission.

\section{EMERGING LITERATURE}

There is also emerging evidence that the preoperative inflammatory profile of a patient might have a significant influence on postoperative outcomes after bariatric surgery. In the Surgical Treatment and Medications Potentially Eradicate Diabetes Efficiently (STAMPEDE) trial, preoperative C-reactive protein (CRP) was analyzed as a predictor of remission: CRP is an annular, pentameric protein produced by the liver in response to inflammation. The study reported preoperative high-sensitivity CRP was $4.3 \mathrm{mg} / \mathrm{L}$ and dropped by $84 \%$ to $0.6 \mathrm{mg} / \mathrm{L}$ at 12 months postoperatively; however, this change was not significantly correlated with remission. ${ }^{4}$ More recent studies, which have generally included small numbers of patients and had retrospective designs, have analyzed $\mathrm{CRP}$ and other markers of inflammation, such as the baseline neutrophil-to-lymphocyte ratio, and found these to be significant predictors of remission. Larger well-designed studies are needed to validate these findings.

\section{CONCLUSION}

The current evidence as summarized above indicates preoperative variables that reflect $\beta$-cell function and its surrogates, namely the DoD and plasma C-peptide concentration, are the most significant independent predictors of T2DM remission. There was a trend in most studies for lack of insulin use and lower baseline $\mathrm{HbAlc}$ to indicate a significantly greater probability of remission. These two variables are best described as indirect predictors of residual $\beta$-cell function and consequently of remission. The evidence also suggests surrogates of the severity of obesity, such as BMI and age at surgery, have a predictive value above specific cutoff values. The cutoff for age likely lies somewhere between 40 and 50 years, above which point age becomes a significant predictor of poorer T2DM outcome. Patients with BMI values between 40 to $50 \mathrm{~kg} / \mathrm{m}^{2}$ have a higher probability of achieving remission postoperatively. The role of gen- der remains controversial, while only a limited number of studies have considered race.

An obvious gap in the literature is the lack of data on the relationship between preoperative interventions and T2DM remission. The only preoperative intervention discussed above is the optimization of $\mathrm{HbAlc}$ prior to surgery. There are limited data addressing the effects of preoperative weight loss as a dependent (by reducing baseline $\mathrm{HbAlc}$ ) or independent predictor of remission.

There is also very limited evidence of the effects of a preoperative psychiatric diagnosis on T2DM remission. Madsen et al. ${ }^{18}$ found a preoperative history of depression was unrelated to T2DM remission. However, in most large studies, data and analysis of the effect of psychiatric diagnosis on remission remain relatively scarce.

\section{CONFLICTS OF INTEREST}

The authors declare no conflict of interest.

\section{ACKNOWLEDGMENTS}

We thank the Bariatric Surgery Department at the University Hospital, Ayr, Scotland, UK for their assistance.

\section{AUTHOR CONTRIBUTIONS}

Study concept and design: JF and AA; acquisition of data: JF; analysis and interpretation of data: JF and UC; drafting of the manuscript: JF; critical revision of the manuscript: JR, UC, $A B$, and AA; statistical analysis: $\mathrm{AB}$; administrative, technical, or material support: JR and $A B$; and study supervision: $A A$.

\section{REFERENCES}

1. World Health Organization. Obesity and overweight [Internet]. Geneva: World Health Organization; 2020 [cited 2020 May 2]. Available from: https://www.who.int/news-room/ fact-sheets/detail/obesity-and-overweight.

2. Lean ME, Leslie WS, Barnes AC, Brosnahan N, Thom G, McCombie L, et al. Primary care-led weight management for remission of type 2 diabetes (DiRECT): an open-label, clus- 
ter-randomised trial. Lancet 2018;391:541-51.

3. Li G, Zhang P, Wang J, Gregg EW, Yang W, Gong Q, et al. The long-term effect of lifestyle interventions to prevent diabetes in the China Da Qing Diabetes Prevention Study: a 20-year follow-up study. Lancet 2008;371:1783-9.

4. Schauer PR, Bhatt DL, Kirwan JP, Wolski K, Aminian A, Brethauer SA, et al. Bariatric surgery versus intensive medical therapy for diabetes: 5-year outcomes. N Engl J Med 2017;376: 641-51.

5. Sjöström L, Peltonen M, Jacobson P, Ahlin S, Andersson-Assarsson J, Anveden Å, et al. Association of bariatric surgery with long-term remission of type 2 diabetes and with microvascular and macrovascular complications. JAMA 2014;311: 2297-304.

6. Pories WJ, MacDonald KG Jr, Morgan EJ, Sinha MK, Dohm GL, Swanson MS, et al. Surgical treatment of obesity and its effect on diabetes: 10-y follow-up. Am J Clin Nutr 1992;55(2 Suppl):582S-585S.

7. Tsilingiris D, Koliaki C, Kokkinos A. Remission of type 2 diabetes mellitus after bariatric surgery: fact or fiction? Int J Environ Res Public Health 2019;16:3171.

8. Pories WJ, Swanson MS, MacDonald KG, Long SB, Morris PG, Brown BM, et al. Who would have thought it? An operation proves to be the most effective therapy for adult-onset diabetes mellitus. Ann Surg 1995;222:339-50.

9. Dixon JB, O’Brien PE, Playfair J, Chapman L, Schachter LM, Skinner S, et al. Adjustable gastric banding and conventional therapy for type 2 diabetes: a randomized controlled trial. JAMA 2008;299:316-23.

10. Wittgrove AC, Clark GW. Laparoscopic gastric bypass, Rouxen-Y- 500 patients: technique and results, with 3-60 month follow-up. Obes Surg 2000;10:233-9.

11. Dixon JB, O'Brien PE. Health outcomes of severely obese type 2 diabetic subjects 1 year after laparoscopic adjustable gastric banding. Diabetes Care 2002;25:358-63.

12. Schauer PR, Burguera B, Ikramuddin S, Cottam D, Gourash W, Hamad G, et al. Effect of laparoscopic Roux-en Y gastric bypass on type 2 diabetes mellitus. Ann Surg 2003;238:467-84.

13. Scopinaro N, Marinari GM, Camerini GB, Papadia FS, Adami GF. Specific effects of biliopancreatic diversion on the major components of metabolic syndrome: a long-term follow-up study. Diabetes Care 2005;28:2406-11.

14. Sugerman HJ, Wolfe LG, Sica DA, Clore JN. Diabetes and hypertension in severe obesity and effects of gastric bypassinduced weight loss. Ann Surg 2003;237:751-6.

15. Sjöström L, Narbro K, Sjöström CD, Karason K, Larsson B, Wedel $\mathrm{H}$, et al. Effects of bariatric surgery on mortality in Swedish obese subjects. N Engl J Med 2007;357:741-52.

16. Buse JB, Caprio S, Cefalu WT, Ceriello A, Del Prato S, Inzucchi SE, et al. How do we define cure of diabetes? Diabetes Care 2009;32:2133-5.

17. Aron-Wisnewsky J, Sokolovska N, Liu Y, Comaneshter DS, Vinker S, Pecht T, et al. The advanced-DiaRem score improves prediction of diabetes remission 1 year post-Roux-en-Y gastric bypass. Diabetologia 2017;60:1892-902.

18. Madsen LR, Baggesen LM, Richelsen B, Thomsen RW. Effect of Roux-en-Y gastric bypass surgery on diabetes remission and complications in individuals with type 2 diabetes: a Danish population-based matched cohort study. Diabetologia 2019; 62:611-20.

19. Wang GF, Yan YX, Xu N, Yin D, Hui Y, Zhang JP, et al. Predictive factors of type 2 diabetes mellitus remission following bariatric surgery: a meta-analysis. Obes Surg 2015;25:199-208.

20. Chikunguwo SM, Wolfe LG, Dodson P, Meador JG, Baugh N, Clore JN, et al. Analysis of factors associated with durable remission of diabetes after Roux-en-Y gastric bypass. Surg Obes Relat Dis 2010;6:254-9.

21. Hamza N, Abbas MH, Darwish A, Shafeek Z, New J, Ammori BJ. Predictors of remission of type 2 diabetes mellitus after laparoscopic gastric banding and bypass. Surg Obes Relat Dis 2011;7:691-6.

22. Hayes MT, Hunt LA, Foo J, Tychinskaya Y, Stubbs RS. A model for predicting the resolution of type 2 diabetes in severely obese subjects following Roux-en Y gastric bypass surgery. Obes Surg 2011;21:910-6.

23. Carlsson LM, Peltonen M, Ahlin S, Anveden Å, Bouchard C, Carlsson B, et al. Bariatric surgery and prevention of type 2 diabetes in Swedish obese subjects. N Engl J Med 2012;367: 695-704.

24. Jiménez A, Casamitjana R, Flores L, Viaplana J, Corcelles R, 
Lacy A, et al. Long-term effects of sleeve gastrectomy and Roux-en-Y gastric bypass surgery on type 2 diabetes mellitus in morbidly obese subjects. Ann Surg 2012;256:1023-9.

25. Lee WJ, Hur KY, Lakadawala M, Kasama K, Wong SK, Chen S-C, et al. Predicting success of metabolic surgery: age, body mass index, C-peptide, and duration score. Surg Obes Relat Dis 2013;9:379-84.

26. Arterburn D, Bogart A, Coleman KJ, Haneuse S, Selby JV, Sherwood NE, et al. Comparative effectiveness of bariatric surgery vs. nonsurgical treatment of type 2 diabetes among severely obese adults. Obes Res Clin Pract 2013;7:e258-68.

27. Dixon JB, Chuang LM, Chong K, Chen SC, Lambert GW, Straznicky NE, et al. Predicting the glycemic response to gastric bypass surgery in patients with type 2 diabetes. Diabetes Care 2013;36:20-6.

28. Aarts EO, Janssen J, Janssen IM, Berends FJ, Telting D, de Boer $\mathrm{H}$. Preoperative fasting plasma C-peptide level may help to predict diabetes outcome after gastric bypass surgery. Obes Surg 2013;23:867-73.

29. Ramos-Levi AM, Matia P, Cabrerizo L, Barabash A, SanchezPernaute A, Calle-Pascual AL, et al. Statistical models to predict type 2 diabetes remission after bariatric surgery. J Diabetes 2014;6:472-7.

30. Still CD, Wood GC, Benotti P, Petrick AT, Gabrielsen J, Strodel WE, et al. Preoperative prediction of type 2 diabetes remission after Roux-en-Y gastric bypass surgery: a retrospective cohort study. Lancet Diabetes Endocrinol 2014;2:38-45.

31. Robert M, Ferrand-Gaillard C, Disse E, Espalieu P, Simon C, Laville M, et al. Predictive factors of type 2 diabetes remission 1 year after bariatric surgery: impact of surgical techniques. Obes Surg 2013;23:770-5.

32. English TM, Malkani S, Kinney RL, Omer A, Dziewietin MB, Perugini R. Predicting remission of diabetes after RYGB surgery following intensive management to optimize preoperative glucose control. Obes Surg 2015;25:1-6.

33. Bhasker AG, Remedios C, Batra P, Sood A, Shaikh S, Lakdawala M. Predictors of remission of T2DM and metabolic effects after laparoscopic Roux-en-y gastric bypass in obese Indian diabetics-a 5-year study. Obes Surg 2015;25:1191-7.

34. Panunzi S, Carlsson L, De Gaetano A, Peltonen M, Rice T,
Sjöström L, et al. Determinants of diabetes remission and glycemic control after bariatric surgery. Diabetes Care 2016;39: 166-74.

35. Panunzi S, De Gaetano A, Carnicelli A, Mingrone G. Predictors of remission of diabetes mellitus in severely obese individuals undergoing bariatric surgery: do BMI or procedure choice matter? A meta-analysis. Ann Surg 2015;261:459-67.

36. Ikramuddin S, Billington CJ, Lee WJ, Bantle JP, Thomas AJ, Connett JE, et al. Roux-en-Y gastric bypass for diabetes (the Diabetes Surgery Study): 2-year outcomes of a 5-year, randomised, controlled trial. Lancet Diabetes Endocrinol 2015; 3:413-22.

37. Park JY, Kim YJ. Prediction of diabetes remission in morbidly obese patients after Roux-en-Y gastric bypass. Obes Surg 2016; 26:749-56.

38. Scopinaro N, Adami GF, Bruzzi P, Cordera R. Prediction of diabetes remission at long term following biliopancreatic diversion. Obes Surg 2017;27:1705-8.

39. Praveen Raj P, Bhattacharya S, Kumar SS, Sabnis SC, Parthasarathi R, Swamy PD, et al. Do bariatric surgery-related type 2 diabetes remission predictors add clinical value? a study on Asian Indian obese diabetics. Obes Surg 2017;27:2113-9.

40. Aminian A, Brethauer SA, Andalib A, Nowacki AS, Jimenez A, Corcelles $\mathrm{R}$, et al. Individualized metabolic surgery score: procedure selection based on diabetes severity. Ann Surg 2017; 266:650-7.

41. Naitoh T, Kasama K, Seki Y, Ohta M, Oshiro T, Sasaki A, et al. Efficacy of sleeve gastrectomy with duodenal-jejunal bypass for the treatment of obese severe diabetes patients in Japan: a retrospective multicenter study. Obes Surg 2018;28: 497-505.

42. Huang X, Liu T, Zhong M, Cheng Y, Hu S, Liu S. Predictors of glycemic control after sleeve gastrectomy versus Roux-en-Y gastric bypass: a meta-analysis, meta-regression, and systematic review. Surg Obes Relat Dis 2018;14:1822-31.

43. Stallard R, Sahai V, Drover JW, Chun S, Keresztes C. Defining and using preoperative predictors of diabetic remission following bariatric surgery. JPEN J Parenter Enteral Nutr 2018;42: 573-80.

44. Pucci A, Tymoszuk U, Cheung WH, Makaronidis JM, Scho- 
les S, Tharakan G, et al. Type 2 diabetes remission 2 years post Roux-en-Y gastric bypass and sleeve gastrectomy: the role of the weight loss and comparison of DiaRem and DiaBetter scores. Diabet Med 2018;35:360-7.

45. Shen SC, Wang W, Tam KW, Chen HA, Lin YK, Wang SY, et al. Validating risk prediction models of diabetes remission after sleeve gastrectomy. Obes Surg 2019;29:221-9.

46. Sharma M, Nazareth I, Petersen I. Trends in incidence, prevalence and prescribing in type 2 diabetes mellitus between 2000 and 2013 in primary care: a retrospective cohort study. BMJ Open 2016;6:e010210.
47. Chong K, Ikramuddin S, Lee WJ, Billington CJ, Bantle JP, Wang $\mathrm{Q}$, et al. National differences in remission of type 2 diabetes mellitus after Roux-en-Y gastric bypass surgery-subgroup analysis of 2-year results of the diabetes surgery study comparing Taiwanese with Americans with mild obesity (BMI 30-35 kg/m2). Obes Surg 2017;27:1189-95.

48. Admiraal WM, Celik F, Gerdes VE, Dallal RM, Hoekstra JB, Holleman F. Ethnic differences in weight loss and diabetes remission after bariatric surgery: a meta-analysis. Diabetes Care 2012;35:1951-8. 